\title{
Ultrasound-assisted extraction for enhanced retention of physicochemical properties of garlic powder obtained by spray-drying
}

\author{
P. Poojitha ${ }^{1}$, Jolius Gimbun ${ }^{2 *}$, Afiqah Yeop ${ }^{2}$, K. A. Athmaselvi ${ }^{3}$ \\ ${ }^{1}$ Department of Food Process Engineering, SRM Institute of Science and Technology, Kattankulathur, Chennai, India. \\ ${ }^{2}$ Centre of Excellence for Advanced Research in Fluid Flow CARIFF, Universiti Malaysia Pahang, Gambang, Malaysia. \\ ${ }^{3}$ Centre for Excellance in Grain Science, Indian Institute of Food Process Technology, Ministry of Food Processing Industries, Government of India, Thanjavur, India.
}

\begin{tabular}{l}
\hline ARTICLE INFO \\
\hline Received on: $11 / 12 / 2019$ \\
Accepted on: $15 / 03 / 2020$ \\
Available online: $06 / 05 / 2020$
\end{tabular}

Key words:

Garlic, ultrasound-

assisted extraction,

drying, maltodextrin,

physicochemical properties.

\begin{abstract}
This work aims to produce garlic powder with the retention of physicochemical properties by using different methods. Garlic is extracted by an ultrasonic-assisted extraction technique to remove the undesired compounds. In this study, garlic powder is incurred through freeze-drying and spray-drying with maltodextrin as a carrier agent. To compare the efficiency of two drying techniques, garlic is dried without maltodextrin. This study is intended to find a technique to get garlic powder with the best quality. The physicochemical and microstructural properties of the garlic powder obtained were analyzed and compared. It was found that garlic powder spray-dried with maltodextrin has the highest retention of physicochemical properties compared to those treated with other techniques. Although freeze-dried and spray-dried powder developed without carrier agent could maintain the flavor and color, they failed to hold the structure and formed into clusters soon after they are exposed to air. Thus, the obtained results showed spray-drying with maltodextrin as the best drying technology for the maintenance of its physical and chemical properties.
\end{abstract}

\section{INTRODUCTION}

Enhancement in the intake of herbs, fruits, and vegetables lowers the endangerment caused by diseases. Garlic is an allium species that has been considered broadly for its health benefits. Garlic is a bulb-shaped plant with a pungent smell and therapeutic properties (Rivlin, 2001). It is an agricultural product that has a rich source of phenolic materials, phosphorous, potassium, sulfur, selenium, zinc, Vitamins A and C, and a lesser degree of sodium, manganese, and calcium (Brewster, 1977). It consists of bioactive components significant for medicinal properties (Macpherson et al., 2005). It provides substantial benefits in reducing blood pressure (Xiong et al., 2015; Wang et al., 2015) and low-density lipoprotein oxidation (Lau, 2006). In old times, garlic has been

"Corresponding Author

Jolius Gimbun, Centre of Excellence for Advanced Research in Fluid Flow (CARIFF), Universiti Malaysia Pahang, Gambang, Pahang, Malaysia. E-mail:jolius@ump.edu.my utilized as a curative for wounds, flatulence, intestinal discomforts, and other ailments. Garlic is potentially formulated with a selfprotective mechanism against microbial growth. There are many active compounds present in garlic along with other compounds. The activity of these compounds occurs when the garlic bulb is crushed, thereby causing the release of alliinase enzyme which plays a major role in enzymatic reaction required for the production of thiosulfinates. Alliin gathers in the whole garlic naturally when stored at the cool temperature. Garlic is well known for its odor, which comes from alliin and other sulfur compounds. It contains more sulfur compounds of about $1.1-3.5 \%$ when compared with onions which have $0.4-1.2 \%$ (Patra, 2012). These compounds lose their nature when exposed to heat and oxygen. During processing, entire garlic is converted into organosulfur compounds in a short period. It is a long-known fact that the extraction of food can enhance potentiality and wipe out displeasing features such as acidic, irritating, and oxidizing components.

The traditional method of the extraction of garlic has certain disadvantages of long extraction time, degradation of 
thermally stable constituents, and so on. To overcome this problem, an ultrasound-assisted extraction method is used. Ultrasoundassisted extraction is a key technology, in which sustainable green chemistry and extraction are achieved in less time with high efficacy.

Spoilage occurring postharvest causes a fast degradation of product quality, resulting in wastage. Drying is one of the promising ways, which can decrease the expense of packaging, storage, and transportation. It also restricts losses as the dried powders have high stability than liquid foods. Juices from vegetables and fruits can be preserved for months, whereas powder products can be stored for years depending on packaging and storage condition. Various types of drying techniques are available in industries. Spray-drying, foam-mat drying, and freeze-drying are considered as the most effective methods for the production of fruit and vegetable powders. Spray-drying is found to be the efficient one used in the food industry, among many encapsulation methods (Pang et al., 2014; Reineccius, 2004). In the spray-drying chamber, fine liquid droplets get large surface area through atomization that causes the production of sphericalshaped powders with longer shelf life (Beck-Broichsitter et al., 2011). However, fruit and vegetable juices are difficult to spray dry as it contains sugar, which leads to stickiness and low glass transition temperature that affects the drying process. Many studies were reported in which spray-drying without carrier agent caused a less powder production. To overcome this, encapsulation is done by using maltodextrin as carrier material (Quek et al., 2007). Encapsulation is a method used to increase the yield of the product, resulting in a powder form with enhanced shelf life. Encapsulation method is used to protect the sensitive active compounds responsible for flavor and aroma (Ahmed et al., 2010; Borgogna et al., 2010; Jafari et al., 2008; Medina-Torres et al., 2013; Saénz et al., 2009). These active compounds are packed in a matrix during encapsulation (Akhavan et al., 2014). This process improves the quality of the product and protects against ambient condition and easy maintenance (Deladino et al., 2008; Shu et al., 2006). One of the important parts in microencapsulation is the selection of wall material (Pang et al., 2014). Some of the commonly used encapsulation agents in plant-related food products are maltodextrin and gum arabic (Bhusari et al., 2014; Fazaeli et al., 2012; Turchiuli et al., 2014). Maltodextrin, a food ingredient, is the most commonly used agent in the food industry. It is a solid matrix formed by carbohydrates which are amorphous and are efficient in stabilizing nutrients and bioactive compounds (Roos, 2010). In addition to that, maltodextrin improves the wettability and density of the encapsulant. Freezedrying is also used as a method to obtain a powdered form of food. Low-temperature drying methods such as freeze-drying are based on the assumption that it does not alter the phytochemical nature of the food. Freeze-drying is also known as lyophilization or cryodesiccation, and it is considered as the best method for drying thermosensitive substances. Although it is costly compared to other drying methods, it has the capability to retain the value of nutraceutical extract and other heat-sensitive compounds justifying the cost (Lopez-Quiroga et al., 2012). In freeze-drying, crystallization of water in ice crystals occurs under pressure, which sublimates afterward leading to the formation of porous structure in the dried product. During this process, substances are not exposed to high temperatures, thereby preserving the nutritious characteristics and enhancing the shelf life of the product. The problem with freeze-drying is the loss of texture and an increase in crumbliness (Chassagne-Berces et al., 2009; Ratti, 2001; Van Buggenhout et al., 2006). While it is proven that even though freeze-drying prevents thermal degradation, phytochemicals are degraded by polyphenol oxidase enzymes (Devic et al., 2010).

This study aims to study the best method to obtain a garlic powder with better retainment of physicochemical properties. To eliminate the unwanted compounds, garlic is extracted by ultrasonic-assisted extraction. The extract is made into powdered form to stabilize the shelf life. This is done by spray-drying with and without maltodextrin and freeze-drying without maltodextrin. The main objective is to produce garlic powder by microencapsulation of garlic extract with maltodextrin and without maltodextrin and also to obtain by freeze-drying without maltodextrin. This study focuses on the comparative analyses on the physicochemical properties of the garlic powder obtained by these three methods. Furthermore, the microstructure of garlic powder obtained by differential methods is studied.

\section{MATERIALS AND METHODS}

\section{Sample preparation}

Fresh garlic is purchased from a local supermarket in Kuantan, Malaysia. Garlic bulb was separated into cloves, manually peeled, and then ground to a pulp with $50 \mathrm{ml}$ of water. The pulp was weighed and mixed with $100 \mathrm{ml}$ of water. It is then extracted by ultrasonication.

\section{Ultrasonic-assisted extraction of garlic}

Ultrasonic-assisted extraction was carried out in a double frequency desk-top ultrasonic processor (Model: QSONICA/ Q700, USA). Garlic pulp was extracted by ultrasonication at 50 amplitude for 50 minutes. Moreover, the final temperature after extraction was found to be $84^{\circ} \mathrm{C}$, with power as $57 \mathrm{w}$ and energy as $102,142 \mathrm{~J}$. After extraction, the garlic pulp was centrifuged at $4^{\circ} \mathrm{C}, 10,000 \mathrm{rpm}$ for 15 minutes. The supernatant was then filtered from residue. The garlic extract is concentrated at $40^{\circ} \mathrm{C}$ and 80 rpm using a rotary evaporator

\section{Spray-drying of garlic}

The feed solution for spray-drying of garlic extract with maltodextrin was prepared using 20\% maltodextrin (obtained from maltodextrin with a dextrose equivalence of 16.5-19.5) as a carrier material. Similarly, a feed solution containing garlic extract without maltodextrin is prepared. Garlic extract was spraydried with maltodextrin and without maltodextrin. Once the feed mixture was prepared, the drying experiment was carried out. Spray-drying was performed with an inlet temperature of $182^{\circ} \mathrm{C}$ and an outlet temperature of $93^{\circ} \mathrm{C}$. A $1-\mathrm{mm}$ diameter nozzle was used to produce the spray-dried garlic powder. The pressure of the liquid feed was six bar with a liquid flow rate of $0.0125 \mathrm{~kg} / \mathrm{s}$.

\section{Freeze-drying of garlic}

The concentrated garlic extract was prefreezed at $-80^{\circ} \mathrm{C}$ for 48 hours. Freeze-drying is performed using Alpha 2-4 CDplusAlchrist Freeze drier. The drying took place with a vacuum 
pressure of 0.012 bar at $-60^{\circ} \mathrm{C}$ for 48 hours. The dried product was stored in a desiccator.

\section{Moisture content of garlic powder}

The moisture content of the garlic powder was measured using moisture meter (AND MS-70). All samples are analyzed in triplicates.

\section{pH measurement}

The $\mathrm{pH}$ of the reconstituted garlic paste was measured using digital pH meter (Cyber pH 14 L) (Abid et al., 2013).

\section{Acidity}

Total titratable acidity was measured according to the method described (Cristina et al., 1999). The reconstituted garlic paste was filtered and titrated against $0.1 \mathrm{~N} \mathrm{NaOH}$. The following formula was used to calculate the total acid \% in terms of predominant acid present in the garlic, i.e., pyruvic acid (Ranganna, 2010).

Titre value $\times$ Normality of alkali $\times$ Volume made up $\times$

$$
\text { Acidity, } \%=\frac{\text { Equivalent weight of acid }}{\text { Volume of sample taken for estimation } \times} \times 100
$$

\section{Total soluble solids}

Total soluble solids in the reconstituted garlic paste were determined with a hand refractometer (ATAGO PAL -3, Japan) and calibrated using distilled water. The hand refractometer works on the principle of the total refraction of light. About $0.5 \mathrm{ml}$ of the paste was spread on the plate surface, and the value was observed (Abid et al., 2013).

\section{Water solubility index (WSI) and water absorption capacity (WAC)}

About $0.5 \mathrm{~g}$ of powder was mixed with $6 \mathrm{ml}$ of distilled water in a centrifuge tube and was centrifuged at 3,000 rpm for 10 minutes. The supernatant was dried at $105^{\circ} \mathrm{C}$ to obtain a dry solid weight, and the residue was also weighed (Anderson and Griffin, 1969).

Water solubility index, $($ WSI $)=\frac{(\text { Weight of dry solid in supernatant })}{(\text { Weight of dry sample })} \times 100$

Water absorption capicity, (WAC)

$$
=\frac{(\text { Weight of wet sediment })}{(\text { Weight of dry sample })-(\text { Weight of dry solids })}
$$

\section{Bulk density, tap density, and porosity}

About $5 \mathrm{~g}$ of the garlic powder is taken in a measuring jar with a capacity of $25 \mathrm{ml}$. Bulk density was calculated in $\mathrm{m} / \mathrm{V}(\mathrm{Kg} /$ $\left.\mathrm{m}^{3}\right)$. Tapping the measuring jar will provide a tap density which is also expressed as $\mathrm{m} / \mathrm{V}\left(\mathrm{Kg} / \mathrm{m}^{3}\right)$. Porosity is the void space between particles and is expressed in terms of percentage (Caparino et al., 2012).

$$
\text { Porosity }=\frac{\rho_{\mathrm{t}}-\rho_{\mathrm{b}}}{\rho_{\mathrm{t}}}
$$

where $\rho_{\mathrm{t}}$ is the tap density, and $\rho_{\mathrm{b}}$ is the bulk density.

\section{Flowability studies}

Hausner's ratio (HR) was used to understand the flowability of the dried powders. It was determined by calculating the ratio between tap density and bulk density (Kotaro et al., 2001).

$$
\text { Hausner's ratio, } \mathrm{HR}=\frac{\rho_{\mathrm{t}}}{\rho_{\mathrm{b}}}
$$

\section{Water activity}

Water activity $\left(a_{w}\right)$ was determined using the method of Caparino (Caparino et al., 2012). About $2 \mathrm{~g}$ of the garlic powder was placed in a cup and placed inside the water activity machine until it gave a beep sound, after which the water activity value was noted.

\section{Color analysis}

Color measurements of the garlic were carried out using a HunterLab (ColorQuest), based on three variables, namely, L, a, and $b$. The $L$ value signifies the lightness, the a value represents greenness and redness, and the $b$ value signifies a change from blueness to yellowness. The instrument was calibrated against a standard white reference tile (Trirattanapikul and Phoungchandang, 2014).

\section{Morphological studies}

The microstructure of the sample was evaluated with a scanning electron microscope (SEM) (Hitachi TM3030, Japan). The samples were mounted on specimen stubs with double-sided adhesive carbon tapes. The specimen was coated with gold and was operated at $15 \mathrm{kV}$ with a magnification of $500 \times$. The system is also equipped with a silicon drift detector-based energy dispersive $\mathrm{X}$-ray (Oxford Instruments).

\section{RESULTS AND DISCUSSION}

\section{Ultrasound-assisted extraction of garlic}

The extraction of garlic was done by ultrasonication method, by which the resultant extract was centrifuged, filtered, and concentrated by rotary evaporation as shown in Figure 1. The volume of the final extract was about $700 \mathrm{ml}$, which has been parted into three for freeze-drying, spray-drying with maltodextrin, and spray-drying without maltodextrin.

\section{Effect of different drying techniques on the properties of garlic powder}

The spray-drying of garlic extract with and without maltodextrin was carried out. The garlic extract spray-dried without maltodextrin took a drying time of 25 minutes, which was less when compared to drying of garlic extract with maltodextrin which took about 40 minutes. As shown in Figure 2, garlic powder obtained without maltodextrin seems to be more sticky and devoid of lightness than that of spray-dried garlic powder 
with maltodextrin. On the other hand, freeze-dried garlic powder was found to have a crystalline texture and more pungency as shown in Figure 2. Apart from this, a comparative analysis of the physicochemical properties of the garlic powder obtained by spray and freeze-drying was done.

\section{Physicochemical analyses of garlic powder}

Garlic powder obtained by spray- and freeze-drying was analyzed for physical parameters including bulk density, tapped density, flowability, porosity, water activity, moisture content, WSI, WAC, color, and biochemical analyses including $\mathrm{pH}$, acidity, Total Soluble Solids (TSS) by the Association of Official Analytical Chemists methods, as shown in Table 1.

Moisture content is a significant property of powder, which is associated with the efficiency of drying. The moisture content of the garlic powder obtained by freeze-drying is about $15.07 \%$. It could be due to the porous nature of the freeze-dried powder, which tends to absorb the surrounding moisture. In the case of spray-drying, garlic powder obtained with maltodextrin as a carrier agent has a higher moisture content $(16.45 \%)$ than garlic powder obtained without maltodextrin (10.26\%). This could be due to the high retention capacity of starch derivatives in maltodextrin. Similar results were also reported in spray-dried lemongrass, which had a moisture content ranging from $8.49 \%$ to $13.11 \%$ concerning inlet temperature (Tuyet and Ha, 2018). Moisture content has a direct effect on the water activity of the product, and lesser the moisture content less will be the water activity and more will be the shelf life of the product. Water activity shows the microbial growth stability, which is important for the long-term storage of any product. Garlic powder with maltodextrin had the highest water activity. Spray-dried garlic powder without maltodextrin is found to have a low water activity of 0.213 than that of freeze-dried powder having 0.269 . In the case of the freeze-drying process, a more porous structure was formed, which resulted in higher moisture content and water activity values (Franceschinis et al., 2014). However, the water activity values were within the expected range $(<0.6)$ of dried products, indicating that these products are safe from microbial growth (Subtil et al., 2014). A similar relation was observed in the case of orange juice powder (Islam et al., 2015) and carrot powder (Janiszewska-Turak et al., 2017).

The cognition of food density is essential for processing, packaging, shipping, and storage. In general, the powder obtained with maltodextrin expressed higher bulk and tapped density. The change in these properties is mainly due to the solid content, viscosity, and temperature of the feed. There is no significant difference between the density of freezedried garlic powder and spray-dried powder with maltodextrin. During the process of drying, moisture removal tends to increase the solid content. Spray-dried garlic powder with maltodextrin is found to have more density when compared to those treated with the other two methods. The addition of maltodextrin has increased the tapped and bulk density of the product. The bulk and tapped densities of the freeze-dried sample were also more

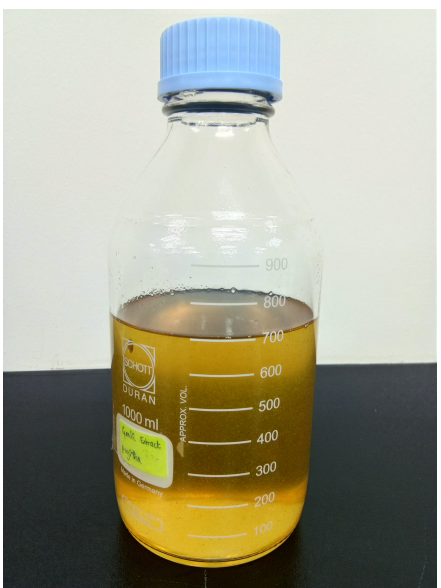

Figure 1. Garlic extract obtained from ultrasonication.

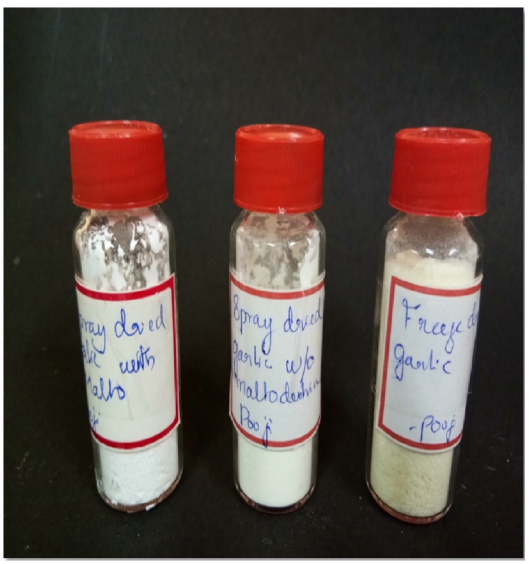

Figure 2. Representation of garlic powder.

Table 1. Physical properties of garlic powder.

\begin{tabular}{lccc}
\hline & \multicolumn{3}{c}{ Garlic powder } \\
\hline Properties & Freeze-dried & $\begin{array}{c}\text { Spray-dried with } \\
\text { Maltodextrin }\end{array}$ & $\begin{array}{c}\text { Spray-dried without } \\
\text { Maltodextrin }\end{array}$ \\
\hline Moisture content (\%) & $15.07 \pm 0.03^{\mathrm{a}}$ & $16.45 \pm 0.04^{\mathrm{b}}$ & $10.26 \pm 0.03$ \\
Water activity (aw) & $0.269 \pm 0.02^{\mathrm{a}}$ & $0.357 \pm 0.01^{\mathrm{c}}$ & $0.213 \pm 0.04^{\mathrm{b}}$ \\
Bulk density (g/ml) & $0.35 \pm 0.11^{\mathrm{a}}$ & $0.36 \pm 0.13^{\mathrm{a}}$ & $0.266 \pm 0.1^{\mathrm{b}}$ \\
Tapped density (g/ml) & $0.55 \pm 0.02^{\mathrm{a}}$ & $0.7 \pm 0.03^{\mathrm{b}}$ & $0.33 \pm 0.04^{\mathrm{c}}$ \\
Porosity & $34.54 \pm 0.2^{\mathrm{b}}$ & $40.05 \pm 0.04^{\mathrm{a}}$ & $23.31 \pm 0.1^{\mathrm{c}}$ \\
HR & $1.5 \pm 0.02^{\mathrm{b}}$ & $2.1 \pm 0.04^{\mathrm{a}}$ & $1.24 \pm 0.02^{\mathrm{c}}$ \\
& & $98.27 \pm 0.05^{\mathrm{a}}$ & $90.02 \pm 0.17^{\mathrm{b}}$ \\
Colour & $\mathrm{L}$ & $3.47 \pm 0.1^{\mathrm{b}}$ & $7.34 \pm 0.12^{\mathrm{b}}$ \\
pH & $15.34 \pm 0.2^{\mathrm{a}}$ & $5.02^{\mathrm{c}}$ & $5.91 \pm 0.136$ \\
Acidity (\%) & $5.88 \pm 0.236^{\mathrm{a}}$ & $5.70 \pm 0.575^{\mathrm{b}}$ & $0.88 \pm 0.176^{\mathrm{b}}$ \\
TSS ( ${ }^{\mathrm{b}}$ Brix) & $1.99 \pm 1.07^{\mathrm{a}}$ & $1.056 \pm 0.02^{\mathrm{c}}$ & $0.93 \pm 0.302^{\mathrm{c}}$ \\
WAC & $2 \pm 0.72^{\mathrm{b}}$ & $2.73 \pm 1.27^{\mathrm{a}}$ & $3.8 \pm 0.05^{\mathrm{b}}$ \\
WSI & $5.83 \pm 0.02^{\mathrm{a}}$ & $2.5 \pm 0.03^{\mathrm{c}}$ & $88.2 \pm 0.31^{\mathrm{a}}$ \\
\hline
\end{tabular}

TSS $=$ Total soluble solids; WAC $=$ Water absorption capacity; WSI $=$ Water solubility index. 
due to the crystalline structure of the powder, which had bigger particles. Higher bulk density has advantages that the product can be stored in smaller containers. Lower the bulk density, more jammed will be the stir within the product that causes oxidation and reduces storage period. In this study, bulk and tapped density values were in proximity with the values of amaranthus betacyanin pigment powder $(0.56-0.64 \mathrm{~g} / \mathrm{ml})(\mathrm{Cai}$ and Corke, 2000) and beetroot juice concentrate $(0.48-0.58$ $\mathrm{g} / \mathrm{ml}$ ) (Bazaria and Kumar, 2016). Similarly, the bulk density of spray-dried mao powder was in the range of $0.5-0.65 \mathrm{~g} / \mathrm{ml}$ (Suravanichnirachorn et al., 2018).

Bulk density and tapped density have a direct effect on porosity and flowability of the garlic powder. Spray-dried garlic powder without maltodextrin is found to have less void space than others due to less density. Less the HR, more will be the flowability of the product. Due to less moisture content and more solid content, spray-dried garlic powder without maltodextrin is found to have good flowability than other treatments. Flowability is also attributed to size, surface, and chemical nature of the particle (Emery et al., 2009, Lumay et al., 2012). Color is an important factor for the overall acceptability of the product. Hence, it is expected to remain the same even after drying. There was no significant difference between the spray-dried and freeze-dried garlic powder without maltodextrin. However, the addition of carrier material maltodextrin influenced the lightness of the powder. Spraydried garlic powder with maltodextrin had higher $L$ value and reduced $a^{*}$ and $b^{*}$ value, whereas spray-dried powder without maltodextrin and freeze-dried powder have higher $\mathrm{a}^{*}$ and $b^{*}$ value indicating the non-enzymatic browning reaction. Moreover, another factor that may explain the differences in the color attributes is the different water content of the biomasses since drying processes modify the surface of a product altering its reflectiveness and color. During spray-drying, $a^{*}$ decreased as $\mathrm{L}^{*}$ increased because oxidation of pigments increasingly reveals the white color of the maltodextrin. The level of nonenzymatic browning and amount of color indicators is based on the process parameters including temperature and time (Quek et al., 2007). The $\mathrm{pH}$ of the garlic before drying was 3.9, with an acidity $\%$ of 2.1 . The $\mathrm{pH}$ increased after drying as $5.8,5.7$, and 5.91 leading to a reduction in the acidity of about $1.99 \%, 1.05 \%$, and $0.88 \%$ in the form of pyruvic acid in freeze-dried, spraydried with maltodextrin, and spray-dried without maltodextrin garlic powder, respectively. This could be due to the loss of acid that occurs due to evaporation happening during the drying process. Similar results were also reported in freeze-dried guava puree (Askar et al., 1992). There was a significant difference in the Brix between freeze-dried powder and spray-dried powder without maltodextrin. The increase in Brix happens as a result of increased concentration along with maltodextrin hydrolysis during the process of drying (Mahendran, 2010). A WSI of a powder represents the ability to dissolve in water. Solubility is based on the degradation of components present in the garlic powder. There was no significant difference between freezedried powder $(88.6 \%)$ and garlic spray-dried powder without maltodextrin (88.2\%). However, spray-dried garlic powder with maltodextrin showed a high WSI value of about $98 \%$, which could be due to the presence of maltodextrin. A similar trend was also reported in sugarcane juice powder, in which it is explained that the increased water solubility is due to low protein content. High WSI was observed in apple juice concentrate (90.6798.69\%) (Sarabandi et al., 2018) and jamun fruit juice powder (87.67-99.67\%) (Santhalakshmy et al., 2015). The results were also similar to Cano-Chauca et al. (2005), where the effect of different carrier materials on the solubility of mango juice powder is studied. WAC is an important property in powder, representing its ability to reassociate with water. It depends on the carrier material, hydrophilic groups on the surface of the particle, and encapsulating compounds. WAC is found to be more in freeze-dried garlic powder (5.83), due to easy absorption of moisture from the surrounding causing stickiness in the powder. Similar results were observed in Martinelli et al. (2007), where added maltodextrin reduced the water absorption by balancing hydrophilic and hydrophobic sites. In spray-dried garlic powder with and without maltodextrin, WAC was 2.5 and 3.8 , respectively. Powder with high water solubility will have decreased WAC or vice versa (Ahmed et al., 2010).

\section{SEM images}

The microscopic studies show the external morphology of the garlic powder obtained by freeze-drying and spray-drying with and without maltodextrin, as shown in Figure 3a-c. SEM images the mixtures of particles with a different surface structure and shape. In the case of spray-drying, garlic powder produced with maltodextrin showed as spherical particles with a smooth surface. This is the morphology that is commonly presented by spray-dried powders with maltodextrin. It is a beneficial structure as it has lower permeability, increased protection, and better retention of bioactive compounds. A similar structure was also observed in spray-dried tamarind powder. In spray-dried garlic powder without maltodextrin, irregularly shaped particles with shrinkage on its surface were obtained because of the rapid constitution of crust on the droplet surface. Date powder obtained with maltodextrin as a carrier agent showed a similar structure of uniform, globular structure with agglomerates (Manickavasagan et al., 2015). A change in the size of the particle is a satisfactory quality as it supports that there is a significant effect of maltodextrin on the morphology of garlic powder. An examination of the microstructure of the freeze-dried garlic powder indicates the irregular structure of various sizes. Freeze-dried garlic powder had pores perfused that occurred during the freezing process when ice crystals were formed which got removed throughout the freeze-drying process. The solid state of water during freeze-drying defends the main structure and reduces the change in the shape of the product with minimal shrinkage (Marques et al., 2007). Freeze-drying leads to the production of highly porous powder that can absorb more water from the surrounding (Tsami et al., 1998). A similar trend was also followed when blackberry was freeze-dried and spray-dried (Franceschinis et al., 2014). 

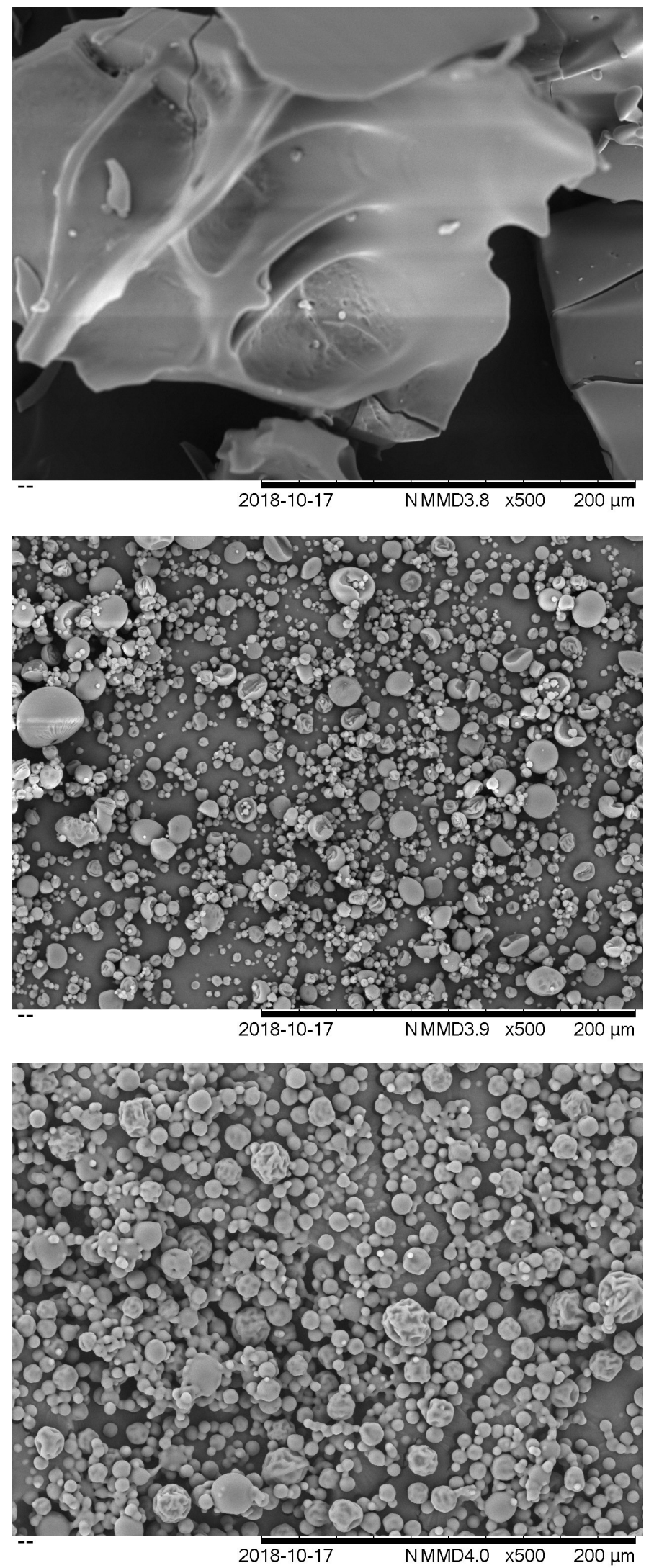

Figure 3. (a) Garlic powder freeze-dried without maltodextrin, (b) garlic powder spray-dried with maltodextrin, (c) garlic powder spray-dried without maltodextrin.

\section{CONCLUSION}

In this study, the quality parameters of the garlic powder extracted by ultrasound-assisted extraction were investigated. Spray-drying and freeze-drying were used as methods to obtain garlic powder, and their efficiencies were compared based on physicochemical properties. The results indicated that ultrasoundassisted garlic dried by spray-drying with maltodextrin is found to maintain the physicochemical properties of garlic. Due to the starch derivative of maltodextrin, the moisture content and water activity were high of about $16.45 \%$ and 0.35 , but it was under the expected range. Although spray-dried garlic produced with maltodextrin had more water activity than that obtained from other methods, it was below the expected range of 0.6. As desired, bulk density was also high in spray-dried powder with maltodextrin, indicating its efficiency in packaging. The microstructural study shows that garlic powder spray-dried with maltodextrin had a spherical smooth surface, which is more acceptable than irregular shaped rough-surfaced powder obtained from spray-drying without maltodextrin.

\section{CONFLICT OF INTEREST}

Authors declare that there are no conflicts of interest.

\section{FINANCIAL SUPPORT}

None.

\section{REFERENCES}

Abid M, Jabbar S, Wu T, Hasim M, Hu B, Shichenglei, et al Effect of ultrasound on different quality parameters of apple juice. Ultrason Sonochem, 2013; 20:1182-7.

Ahmed M, Akter MS, Lee JC, Eun JB. Encapsulation by spray drying of bioactive components, physicochemical and morphological properties from purple sweet potato. LWT- Food Sci Technol, 2010; 43:1307-12.

Akhavan S, Jafari SM, Ghorbani M, Assadpoor E. Spray-drying microencapsulation of anthocyanins by natural biopolymers: a review. Drying Technol, 2014;32: 509-18.

Anderson RC, Conway HF, Pfeifer V, Griffin EL, Anderson R, Conway $\mathrm{H}$, et al. Gelatinization of corn grits by roll and extrusion cooking. Cereal Sci Today, 1969; 14:4-12.

Askar A, El-Sanahy SK, Barrnett M, Salema NA. Production of instant guava drink powder. Food Technol, 1992; 46: 154-61.

Bazaria B, Kumar P. Effect of whey protein concentrate as drying aid and drying parameters on physicochemical and functional properties of spray dried beetroot juice concentrate. Food Biosci, 2016; 14: 21-7.

Beck-Broichsitter M, Schmehl T, Seeger W, Gessler T. Evaluating the controlled release properties of inhaled nanoparticles using isolated, perfused, and ventilated lung models. J Nanomat, 2011; 3:16.

Bhusari S, Muzaffar K, Kumar P. Effect of carrier agents on physical and microstructural properties of spray dried tamarind pulp powder. Powder Technol, 2014; 266:354-64.

Borgogna M, Bellich B, Zorzin L, Lapasin R, Cesàro A. Food microencapsulation of bioactive compounds: rheological and thermal characterisation of non-conventional gelling system. Food Chem, 2010; 122:416-23

Brewster JL. The physiology of the onion. Horticulture Abs, 1977; 47:17-23.

Cai YZ, Corke H. Production and properties of spray-dried amaranthus betacyanin pigments. J Food Sci, 2000; 65:1248-52.

Cano-Chauca M, Stringheta PC, Ramos AM, Cal-Vidal J. Effect of the carriers on the microstructure of mango powder obtained by spray drying and its functional characterization. Innov Food Sci Emer Technol, $2005 ; 6: 420-28$. 
Caparino OA, Tang J, Nindo CI, Sablani SS, Powers JR. Effect of drying methods on the physical properties and microstructures of mango (Philippine 'Carabao' var.) powder. J Food Eng, 2012; 111:135-48.

Chassagne-Berces S, Poirier C, Devaux MF, Fonseca F, Lahaye M, Pigorini G. Changes in texture, cellular structure and cell wall composition in apple tissue as a result of freezing. Food Res Int, 2009; 42:788-97.

Cristina SC, Moura DR, Vitali ADA. A study of water activity and electrical conductivity in fruit juices: influence of temperature and concentration. Braz J Food Technol, 1999; 2:31-8.

Deladino L, Anbinder PS, Navarro AS, Martino MN. Encapsulation of natural antioxidants extracted from Ilex paraguariensis. Carbohyd Polym, 2008; 71:126-34.

Devic E, Guyot S, Daudin JD, Bonazzi C. Kinetics of polyphenol losses during soaking and drying of cider apples. Food Bioprocess Tech, 2010: 3: 867-77.

Emery E, Oliver J, Pugsley T, Sharma J, Zhou J. Flowability of moist pharmaceutical powders. Powder Technol, 2009; 189: 409-15.

Fazaeli M, Emam-Djomeh Z, Ashtari AK, Omid M.. Effect of spray drying conditions and feed composition on the physical properties of black mulberry juice powder. Food Bioprod Process, 2012; 90:667-75.

Franceschinis L, Salvatori DM, Sosa N, Schebor, C. Physical and functional properties of blackberry freeze- and spray-dried powders. Drying Technol, 2014; 32:197-207.

Islam M, Kitamura Y, Yamano Y, Kitamura M. Effect of vacuum spray drying on the physicochemical properties, water sorption and glass transition phenomenon of orange juice powder. J Food Eng, 2015; 169: $130-41$.

Jafari SM, Assadpoor E, He Y, Bhandari B. Encapsulation efficiency of food flavours and oils during spray drying. Drying Technol, $2008 ; 26: 816-35$

Janiszewska-Turak E, Dellarosa N, Tylewicz U, Laghi L, Romani S, Dalla Rosa M, Witrowa-Rajchert D. The influence of carrier material on some physical and structural properties of carrot juice microcapsules. J Food Chem, 2017; 236:134-41.

Kotaro IID, Hayakawa H, Okamoto KA, Danjo Y, Leuenberger $\mathrm{H}$. Evaluation of flow properties of dry powder inhalation of salbutamol sulfate with lactose carrier. Chem Pharma Bull, 2001; 49: 1326-30.

Lau BHS. Suppression of LDL oxidation by garlic compounds is a possible mechanism of cardiovascular health benefit. J Nutr, 2006; 136: 765S-8S.

Lopez-Quiroga E, Antelo LT, Alonso AA. Time-scale modeling and optimal control offreeze-drying. J Food Eng, 2012; 111: 655-66.

Lumay G, Boschini F, Traina K, Bontempi S, Remy JC, Cloots $\mathrm{R}$, et al. Measuring the flowing properties of powders and grains. Powder Technol, 2012; 224:19-27.

Macpherson LJ, Geierstanger BH, Viswanath V, Bandell M, Eid SR, Hwang SW, et al. The pungency of garlic: activation of TRPA1 and TRPV1 in response to allicin. Curr Biol, 2005; 15:929-34.

Mahendran T. Physico-chemical properties and sensory characteristics of dehydrated guava concentrate: effect of drying method and maltodextrin concentration. Trop Agr Res Ext, 2010; 13.

Manickavasagan A, Thangavel K, Dev SRS, Delfiya DA, Nambi E, Orsat V, et al. Physicochemical characteristics of date powder produced in a pilot-scale spray dryer. Drying Technol, 2015; 33:1114-23.

Marques LG, Ferreira MC, Freire JT. Freeze-drying of acerola (Malpighia glabra L.). Chem Eng Process, 2007; 46:451-7.

Martinelli L, Gabas AL, Telis-Romero J. Thermodynamic and quality properties of lemon juice powder as affected by maltodextrin and arabic gum. Drying Technol Int J, 2007; 25: 2035-45.

Medina-Torres L, García-Cruz E, Calderas F, Laredo RG, Sánchez-Olivares G, Gallegos-Infante J, et al. Microencapsulation by spray drying of gallic acid with nopal mucilage (Opuntia ficus indica). LWT-Food Sci Technol, 2013; 50:642-50.

Pang SF, Yusoff MM, Gimbun J. Assessment of phenolic compounds stability and retention during spray drying of Orthosiphon stamineus extract. Food Hydrocolloid, 2014; 37:159-65.

Patra AK. Dietary Phytochemicals and microbes. ISBN 97894-007-3925-3 ISBN 978-94-007-3926-0 (eBook). Springer, Dordrecht, Netherlands, Heidelberg, Germany, New York, NY, London, UK, 2012.

Quek SY, Chok NK, Swedlund P. The physicochemical properties of spray-dried watermelon powders. Chem Eng Process Intensifiers, 2007; 46:386-92.

Ranganna. Hand book of Ananlysis and quality control for fruits and vegetable products. Tata McGraw Hill Education Pvt. Ltd, New Delhi, India, 2010

Ratti C. Hot air and freeze-drying of high-value foods: a review. J Food Eng, 2001; 49:311-19.

Reineccius GA. The spray drying of food flavors. Drying Technol, 2004; 22:1289-324.

Rivlin RS. Historical perspective on the use of garlic. J Nutr, 2001; 131:951S-4S.

Roos YH. Glass transition temperature and its relevance in food processing. Annu Rev Food Sci Technol, 2010; 1:469-96.

Saénz C, Tapia S, Chávez J, Robert P. Microencapsulation by spray drying of bioactive compounds from cactus pear (Opuntia ficusindica). Food Chem, 2009; 114:616-22.

Santhalakshmy S, Don Bosco SJ, Francis S, Sabeena M. Effect of inlet temperature on physicochemical properties of spray-dried jamun fruit juice powder. Powder Technol, 2015; 274:37-43.

Sarabandi KH, Peighambardoust SH, Sadeghi Mahoonak AR, Samaei SP. Effect of different carriers on microstructure and physical characteristics of spray dried apple juice concentrate. J Food Sci Technol, 2018; 55:3098-109.

Shu B, Yu W, Zhao Y, Liu X. Study on microencapsulation of lycopene by spray-drying. J Food Eng, 2006; 76:664-9.

Subtil SF, Rocha-Selmi GA, Thomazini M, Trindade MA, Netto FM, Favaro-Trindade CS. Effect of spray drying on the sensory and physical properties of hydrolysed casein using gum arabic as the carrier. J Food Sci Technol, 2014; 51:2014-21.

Suravanichnirachorn W, Haruthaithanasan V, Suwonsichon S, Sukatta U, Maneeboon T, Chantrapornchai W. Effect of carrier type and concentration on the properties, anthocyanins and antioxidant activity of freeze-dried mao [Antidesma bunius (L.) Spreng] powders. Agr Nat Res, 2018: 52:354-60

Trirattanapikul W, Phoungchandang S. Microwave blanching and drying characteristics of Centella asiatica (L.) urban leaves using tray and heat pump-assisted dehumidified drying. J Food Sci Technol, 2014; 51:3623-34.

Tsami E, Krokida MK, Drouzas AE. Effect of drying method on the sorption characteristics of model fruit powders. J Food Eng, 1998; 38: 381-392.

Turchiuli C, Munguia MJ, Sanchez MH, Ferre HC, Dumoulin E. Use of different supports for oil encapsulation in powder by spray drying. Powder Technol, 2014; 255:103-8.

Tuyet TAT, Ha VHN. Effects of spray-drying temperatures and carriers on physical and antioxidant properties of lemongrass leaf extract powder. Beverages, 2018; 4:84.

Van Buggenhout S, Lille M, Messagie I, Van Loey A, Autio $\mathrm{K}$, Hendrickx M. Impact of pretreatment and freezing conditions on the microstructure of frozen carrots: quantification and relation to texture loss. Eur Food Res Technol, 2006; 222: 543-53.

Wang HP, Yang J, Qin LQ, Yang XJ. Effect of garlic on blood pressure: a meta-analysis. J Clin Hypertens, 2015; 17:223-31. 
Xiong XJ, Wang PQ, Li SJ, Li XK, Zhang YQ, Wang J. Garlic for hypertension: a systematic review and meta-analysis of randomized controlled trials. Phytomedicine, 2015: 22:352-61.

\section{How to cite this article:}

Poojitha P, Gimbun J, Yeop A, Athmaselvi KA. Ultrasoundassisted extraction for enhanced retention of physicochemical properties of garlic powder obtained by spray-drying. J Appl Pharm Sci, 2020; 10(05):127-134. 